\title{
Nivolumab alone and nivolumab plus ipilimumab in recurrent small-cell lung cancer (CheckMate 032): a multicentre, open-label, phase $1 / 2$ trial
}

\author{
Scott J Antonia, José A López-Martin, Johanna Bendell, Patrick A Ott, Matthew Taylor, Joseph Paul Eder, Dirk Jäger, M Catherine Pietanza, \\ Dung T Le, Filippo de Braud, Michael A Morse, Paolo A Ascierto, Leora Horn, Asim Amin, Rathi N Pillai, Jeffry Evans, Ian Chau, Petri Bono, \\ Akin Atmaca, Padmanee Sharma, ChristopherT Harbison, Chen-Sheng Lin, OlafChristensen, Emiliano Calvo
}

\begin{abstract}
Summary
Background Treatments for small-cell lung cancer (SCLC) after failure of platinum-based chemotherapy are limited. We assessed safety and activity of nivolumab and nivolumab plus ipilimumab in patients with SCLC who progressed after one or more previous regimens.
\end{abstract}

Methods The SCLC cohort of this phase 1/2 multicentre, multi-arm, open-label trial was conducted at 23 sites (academic centres and hospitals) in six countries. Eligible patients were 18 years of age or older, had limited-stage or extensive-stage SCLC, and had disease progression after at least one previous platinum-containing regimen. Patients received nivolumab $(3 \mathrm{mg} / \mathrm{kg}$ bodyweight intravenously) every 2 weeks (given until disease progression or unacceptable toxicity), or nivolumab plus ipilimumab $(1 \mathrm{mg} / \mathrm{kg}$ plus $1 \mathrm{mg} / \mathrm{kg}, 1 \mathrm{mg} / \mathrm{kg}$ plus $3 \mathrm{mg} / \mathrm{kg}$, or $3 \mathrm{mg} / \mathrm{kg}$ plus $1 \mathrm{mg} / \mathrm{kg}$, intravenously) every 3 weeks for four cycles, followed by nivolumab $3 \mathrm{mg} / \mathrm{kg}$ every 2 weeks. Patients were either assigned to nivolumab monotherapy or assessed in a dose-escalating safety phase for the nivolumab/ipilimumab combination beginning at nivolumab $1 \mathrm{mg} / \mathrm{kg}$ plus ipilimumab $1 \mathrm{mg} / \mathrm{kg}$. Depending on tolerability, patients were then assigned to nivolumab $1 \mathrm{mg} / \mathrm{kg}$ plus ipilimumab $3 \mathrm{mg} / \mathrm{kg}$ or nivolumab $3 \mathrm{mg} / \mathrm{kg}$ plus ipilimumab $1 \mathrm{mg} / \mathrm{kg}$. The primary endpoint was objective response by investigator assessment. All analyses included patients who were enrolled at least 90 days before database lock. This trial is ongoing; here, we report an interim analysis of the SCLC cohort. This study is registered with ClinicalTrials.gov, number NCT01928394.

Findings Between Nov 18, 2013, and July 28, 2015, 216 patients were enrolled and treated (98 with nivolumab $3 \mathrm{mg} / \mathrm{kg}$ three with nivolumab $1 \mathrm{mg} / \mathrm{kg}$ plus ipilimumab $1 \mathrm{mg} / \mathrm{kg}$, 61 with nivolumab $1 \mathrm{mg} / \mathrm{kg}$ plus ipilimumab $3 \mathrm{mg} / \mathrm{kg}$, and 54 with nivolumab $3 \mathrm{mg} / \mathrm{kg}$ plus ipilimumab $1 \mathrm{mg} / \mathrm{kg}$ ). At database lock on Nov 6, 2015, median follow-up for patients continuing in the study (including those who had died or discontinued treatment) was 198.5 days (IQR 163.0-464.0) for nivolumab $3 \mathrm{mg} / \mathrm{kg}$, 302 days (IQR not calculable) for nivolumab $1 \mathrm{mg} / \mathrm{kg}$ plus ipilimumab $1 \mathrm{mg} / \mathrm{kg}, 361.0$ days (273.0-470.0) for nivolumab $1 \mathrm{mg} / \mathrm{kg}$ plus ipilimumab $3 \mathrm{mg} / \mathrm{kg}$, and $260 \cdot 5$ days $(248 \cdot 0-288 \cdot 0)$ for nivolumab $3 \mathrm{mg} / \mathrm{kg}$ plus ipilimumab $1 \mathrm{mg} / \mathrm{kg}$. An objective response was achieved in ten (10\%) of 98 patients receiving nivolumab $3 \mathrm{mg} / \mathrm{kg}$, one (33\%) of three patients receiving nivolumab $1 \mathrm{mg} / \mathrm{kg}$ plus ipilimumab $1 \mathrm{mg} / \mathrm{kg}, 14(23 \%)$ of 61 receiving nivolumab $1 \mathrm{mg} / \mathrm{kg}$ plus ipilimumab $3 \mathrm{mg} / \mathrm{kg}$, and ten (19\%) of 54 receiving nivolumab $3 \mathrm{mg} / \mathrm{kg}$ plus ipilimumab $1 \mathrm{mg} / \mathrm{kg}$. Grade 3 or 4 treatment-related adverse events occurred in $13(13 \%)$ patients in the nivolumab $3 \mathrm{mg} / \mathrm{kg}$ cohort, $18(30 \%)$ in the nivolumab $1 \mathrm{mg} / \mathrm{kg}$ plus ipilimumab $3 \mathrm{mg} / \mathrm{kg}$ cohort, and ten (19\%) in the nivolumab $3 \mathrm{mg} / \mathrm{kg}$ plus ipilimumab $1 \mathrm{mg} / \mathrm{kg}$ cohort; the most commonly reported grade 3 or 4 treatment-related adverse events were increased lipase (none vs 5 [8\%] vs none) and diarrhoea (none vs $3[5 \%]$ vs 1 [2\%]). No patients in the nivolumab $1 \mathrm{mg} / \mathrm{kg}$ plus ipilimumab $1 \mathrm{mg} / \mathrm{kg}$ cohort had a grade 3 or 4 treatment-related adverse event. Six (6\%) patients in the nivolumab $3 \mathrm{mg} / \mathrm{kg}$ group, seven (11\%) in the nivolumab $1 \mathrm{mg} / \mathrm{kg}$ plus ipilimumab $3 \mathrm{mg} / \mathrm{kg}$ group, and four (7\%) in the nivolumab $3 \mathrm{mg} / \mathrm{kg}$ plus ipilimumab $1 \mathrm{mg} / \mathrm{kg}$ group discontinued treatment due to treatment-related adverse events. Two patients who received nivolumab $1 \mathrm{mg} / \mathrm{kg}$ plus ipilimumab $3 \mathrm{mg} / \mathrm{kg}$ died from treatment-related adverse events (myasthenia gravis and worsening of renal failure), and one patient who received nivolumab $3 \mathrm{mg} / \mathrm{kg}$ plus ipilimumab $1 \mathrm{mg} / \mathrm{kg}$ died from treatment-related pneumonitis.

Interpretation Nivolumab monotherapy and nivolumab plus ipilimumab showed antitumour activity with durable responses and manageable safety profiles in previously treated patients with SCLC. These data suggest a potential new treatment approach for a population of patients with limited treatment options and support the evaluation of nivolumab and nivolumab plus ipilimumab in phase 3 randomised controlled trials in SCLC.

Funding Bristol-Myers Squibb.

\section{Introduction}

Small-cell lung cancer (SCLC), which accounts for roughly $14 \%$ of all lung cancers, is strongly associated with tobacco use and has high mutation rates without known oncogenic drivers. ${ }^{1.2}$ Most patients present with extensive-stage disease characterised by widespread metastases and poor
Lancet Oncol 2016; 17: 883-95 Published Online June 4, 2016 http://dx.doi.org/10.1016/ S1470-2045(16)30098-5

This online publication has been corrected. The corrected version first appeared at thelancet.com/oncology on June 28, 2016

See Comment page 846

H Lee Moffitt Cancer Center \& Research Institute, Tampa, FL, USA (Prof S J Antonia MD); Hospital Universitario 12 de Octubre, Madrid, Spain (J A López-Martin MD); Sarah Cannon Research Institute/Tennessee Oncology, PLLC, Nashville, TN, USA (J Bendell MD); Dana-Farber Cancer Institute, Boston, MA, USA (P A Ott MD); Oregon Health \& Science University Portland, OR, USA (M Taylor MD); Yale Comprehensive Cancer Center, New Haven, $C T$, USA (J P Eder MD); Nationales Centrum für

Tumorerkrankungen (NCT) University Medical Center, Heidelberg, Germany (D Jäger MD); Memorial Sloan Kettering Cancer Center, New York, NY, USA (M C Pietanza MD); The Sidney Kimmel Comprehensive Cancer Center at Johns Hopkins University, Baltimore, MD, USA (DT Le MD); Fondazione IRCCS Istituto Nazionale dei Tumori Milano, Milan, Italy (Prof F de Braud MD); Duke University Medical Center, Durham, NC, USA (Prof M A Morse MD); Istituto Nazionale Tumori Fondazione Pascale, Naples, Italy (PA Ascierto MD); Vanderbilt-Ingram Cancer Center, Nashville, TN, USA (L Horn MD); Levine Cancer Institute, Carolinas Medical Center, Charlotte, NC, USA (A Amin MD); Winship Cancer 


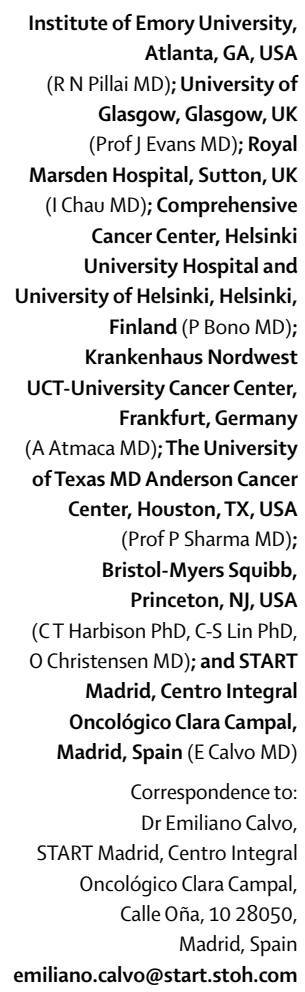

\section{Research in context}

\section{Evidence before this study}

We searched the scientific literature for outcomes following failure of first-line treatment in patients with small-cell lung cancer (SCLC) and available subsequent treatment options. The search terms "SCLC", "recurrent", "relapsed", "second-line", "third-line", "phase 1", "phase 2" and/or "phase 3" were used in PubMed focusing on reports and meta-analyses during the 10 -year period before the start of the trial from Jan 1,2003, to Jan 1, 2013. To investigate the potential for immunotherapy in $\mathrm{SCLC}$, the terms "SCLC" and "immune response",

"immunotherapy", "PD-1", "CTLA-4", "NSCLC", "PD-L1", "nivolumab", "ipilimumab", "MK3475", "lambrolizumab", "MPDL3280A", "MEDI4736", and "tremelimumab" were used to search PubMed, congress abstracts from the annual meetings of the American Association of Cancer Research, American Society of Clinical Oncology, European Cancer Congress, and World Conference on Lung Cancer, and for ongoing trials in ClinicalTrials.gov.

The searches revealed poor survival outcomes for patients with recurrent or relapsed SCLC and no treatment options beyond second line. The following pieces of evidence underscored the rationale for investigating nivolumab and nivolumab plus ipilimumab in SCLC: SCLC is immunogenic, ipilimumab in combination with chemotherapy was active in extensive-disease SCLC, and nivolumab and nivolumab plus ipilimumab showed encouraging activity in non-small-cell lung cancer in phase $1 / 2$ trials.

\section{Added value of this study}

Nivolumab alone and in combination with ipilimumab demonstrated durable objective responses, encouraging overall survival, and manageable safety in patients with advanced SCLC who had progressed after one or more previous regimens. To our knowledge, this is the first trial showing activity of nivolumab and nivolumab plus ipilimumab in SCLC, in a hard-to-treat population of patients with limited treatment options.

Implications of all the available evidence Based on the notable objective responses, the duration of the responses, and the median overall survival seen with nivolumab plus ipilimumab treatment in this patient population, phase 3 studies for nivolumab and nivolumab plus ipilimumab as maintenance therapy (in non-progressing patients) after first-line chemotherapy (CheckMate 451, NCT02538666), and for nivolumab versus chemotherapy as second-line therapy (CheckMate 331, NCT02481830) in SCLC are ongoing. survival. ${ }^{2}$ Although $35-86 \%$ of patients respond to firstline chemotherapy, disease progresses rapidly, and outcomes with second-line treatment are poor. ${ }^{3-6}$

Standard first-line chemotherapy for SCLC is a platinum-etoposide doublet, with topotecan as second-line therapy in the USA and European Union ${ }^{1}$ and amrubicin as second-line therapy in Japan. ${ }^{7}$ Although response with topotecan is achieved in $23 \%$ of platinum-sensitive patients and $9 \%$ of platinum-resistant or refractory patients, these responses are not durable. ${ }^{8}$

Nivolumab, a fully human IgG4 PD-1 immunecheckpoint inhibitor antibody, significantly improved overall survival and had a favourable safety profile compared with docetaxel in two phase 3 studies of patients with non-small-cell lung cancer (NSCLC) who progressed after first-line platinum-based doublet chemotherapy, ${ }^{9,10}$ leading to its approval in the USA and the European Union for treatment of patients with locally advanced or metastatic NSCLC. ${ }^{11}$ Ipilimumab, a fully human IgG1 CTLA-4 immune-checkpoint inhibitor antibody, significantly improved overall survival compared with glycoprotein peptide 100 vaccine in patients with metastatic melanoma, ${ }^{12}$ and ipilimumab plus dacarbazine improved survival over dacarbazine alone in patients with metastatic melanoma. ${ }^{13}$ Ipilimumab is approved in the USA and the European Union for this indication.

Preclinical data suggest that the combination of PD-1 and CTLA-4 receptor blockade might improve antitumour activity, ${ }^{14}$ and the combination of nivolumab plus ipilimumab has demonstrated deep and durable responses in several tumour types. ${ }^{15-17}$ The combination of nivolumab plus ipilimumab is approved in the USA and the European Union for treatment of advanced melanoma. On the basis of efficacy of combination treatment in melanoma, CheckMate 032 was designed as a phase $1 / 2$ trial to investigate the activity and safety of nivolumab as monotherapy or in combination with ipilimumab in several advanced or metastatic solid tumour types. The evaluation of nivolumab monotherapy and the combination of nivolumab and ipilimumab in patients with advanced or metastatic tumours for which no standard of care in advanced lines of treatment exists will potentially generate evidence of antitumour activity as a basis for further clinical development in these tumour types. Here, we report activity, safety, and biomarker analyses for the SCLC cohort.

\section{Methods}

\section{Study design and participants}

This was a multicentre, open-label, two-stage, multi-arm phase 1/2 trial. Patients with SCLC were enrolled at 23 sites (academic centres and hospitals) in six countries (Finland, Germany, Italy, Spain, UK, and USA; appendix p 19). Eligible patients had histologically or cytologically confirmed, limited-stage or extensive-stage SCLC, with progressive disease after at least one platinumbased chemotherapy regimen. Patients with platinumsensitive (relapse $\geq 90$ days after chemotherapy) or 
platinum-resistant (relapse $<90$ days after or during chemotherapy) disease were eligible irrespective of PD-L1 expression. Patients were 18 years of age or older, with an Eastern Cooperative Oncology Group (ECOG) performance status of 0 or 1 and had adequate organ function. Patients were required to have measurable disease per the Response Evaluation Criteria in Solid Tumors (RECIST), version $1.1{ }^{18}$ and baseline tumour biopsy or archival tumour material available for biomarker analyses. Tumour material was acceptable from biopsies performed before the screening period if the biopsy was done up to 3 months before start of treatment and no other systemic cancer therapy was administered in that time. Baseline laboratory tests required to assess eligibility included white blood cell counts, neutrophils, platelets, haemoglobin, serum creatinine, alanine aminotransferase, aspartate aminotransferase, total bilirubin, albumin, lipase, and amylase. Key exclusion criteria included active brain or leptomeningeal metastases, a history of autoimmune disease (except for vitiligo, type 1 diabetes mellitus, residual hypothyroidism due to autoimmune thyroiditis only requiring hormone replacement, or conditions not expected to recur in the absence of an external trigger), the need for immunosuppressive doses of systemic corticosteroids ( $>10 \mathrm{mg}$ per day prednisone equivalents) 2 weeks before study drug administration, and previous treatment with antibodies that modulate T-cell function or checkpoint pathways. Patients were also excluded if they tested positive for hepatitis B virus or HIV, or had unresolved toxic effects from previous anticancer therapies. Patient selection was not based on estimated survival. Median survival for patients with relapsed SCLC has been reported as approximately 3.5-12 months. ${ }^{4}$

The study protocol was approved by an institutional review board or ethics committee at each participating centre. The study was conducted in accordance with the Declaration of Helsinki and Good Clinical Practice guidelines, as defined by the International Conference on Harmonisation. Before performing any study-specific procedures, written informed consent was obtained from all patients.

\section{Procedures}

Using an interactive voice response system, patients with SCLC were enrolled in one of the following four cohorts in a sequential manner, or assigned if more than one cohort was open for enrolment: nivolumab alone $3 \mathrm{mg} / \mathrm{kg}$ bodyweight (nivolumab $3 \mathrm{mg} / \mathrm{kg}$ ) intravenously every 2 weeks until disease progression or unacceptable toxicity, or combination treatment with nivolumab plus ipilimumab intravenously every 3 weeks for four cycles, at dose level 1 (nivolumab $1 \mathrm{mg} / \mathrm{kg}$ plus ipilimumab $1 \mathrm{mg} / \mathrm{kg}$ ), dose level 2 (nivolumab $1 \mathrm{mg} / \mathrm{kg}$ plus ipilimumab $3 \mathrm{mg} / \mathrm{kg}$ ), or dose level $2 \mathrm{~b}$ (nivolumab $3 \mathrm{mg} / \mathrm{kg}$ plus ipilimumab $1 \mathrm{mg} / \mathrm{kg}$ ); all combination regimens were followed by $3 \mathrm{mg} / \mathrm{kg}$ of nivolumab every 2 weeks until disease progression or unacceptable toxicity.
Although the nivolumab $1 \mathrm{mg} / \mathrm{kg}$ plus ipilimumab $3 \mathrm{mg} / \mathrm{kg}$ and nivolumab $3 \mathrm{mg} / \mathrm{kg}$ plus ipilimumab $1 \mathrm{mg} / \mathrm{kg}$ regimens were expected to be tolerable on the basis of previous evidence in other tumour types,,$^{15-17,19,20}$ an initial dose-escalating safety evaluation for the combination groups was done. The first dose cohort (nivolumab $1 \mathrm{mg} / \mathrm{kg}$ plus ipilimumab $1 \mathrm{mg} / \mathrm{kg}$ ) was level 1; we used this dose to confirm the safety of the combination in this patient population. If this was deemed tolerable, we then initiated enrolment and allocation to level 2 (nivolumab $1 \mathrm{mg} / \mathrm{kg}$ plus ipilimumab $3 \mathrm{mg} / \mathrm{kg}$ ). If dose level 2 was deemed not tolerable, enrolment and allocation to dose level $2 \mathrm{~b}$ (nivolumab $3 \mathrm{mg} / \mathrm{kg}$ plus ipilimumab $1 \mathrm{mg} / \mathrm{kg}$ ) was investigated. Patients on active treatment needed to be followed up for at least 6 weeks after the start of study treatment before tolerability of a dose level was determined based on prespecified tolerability assessment criteria, which are detailed in the appendix pp 3, 20. However, tolerability beyond 6 weeks was also taken into consideration. After the highest dose level for further investigation was confirmed in the dose-escalating safety evaluation phase, the combination arms continued enrolling patients.

Considerations for the dosing in the combination cohorts were as follows: the $1 \mathrm{mg} / \mathrm{kg}$ nivolumab plus $3 \mathrm{mg} / \mathrm{kg}$ ipilimumab regimen is the approved dose for the treatment of advanced melanoma; ${ }^{11,21}$ the $3 \mathrm{mg} / \mathrm{kg}$ nivolumab plus $1 \mathrm{mg} / \mathrm{kg}$ ipilimumab regimen was chosen to maximise the nivolumab dose based on nivolumab exposure response data $(1 \quad \mathrm{mg} / \mathrm{kg}$ vs $3 \mathrm{mg} / \mathrm{kg}){ }^{22}$ The safety of the $1 \mathrm{mg} / \mathrm{kg}$ nivolumab plus $3 \mathrm{mg} / \mathrm{kg}$ ipilimumab and the $3 \mathrm{mg} / \mathrm{kg}$ nivolumab plus $1 \mathrm{mg} / \mathrm{kg}$ ipilimumab regimens have been previously assessed in studies of other tumour types. ${ }^{15-17,19,20}$

For combination treatment, nivolumab was given first (60 min infusion), followed by ipilimumab (90 min infusion), as per previous studies evaluating nivolumab plus ipilimumab. ${ }^{19,20}$ Patients received open-label treatment until disease progression or occurrence of unacceptable toxicity. Treatment beyond RECIST (version 1.1)-defined progression was permitted if the patient was tolerating and benefiting from treatment, based on investigator assessment. Patients assigned to the nivolumab $3 \mathrm{mg} / \mathrm{kg}$ group and who progressed could cross over to combination cohorts.

No dose reductions or modifications were permitted for nivolumab or ipilimumab. The criteria for dose delay (until resolution of the treatment-related adverse event to grade 1 or lower) of nivolumab, ipilimumab, or both include the following treatment-related adverse events: grade 2 or worse non-skin events (except for grade 2 fatigue), grade 3 skin events, and grade 3 laboratory abnormalities (except for asymptomatic amylase and lipase increases). If the patient had normal aspartate aminotransferase, alanine aminotransferase, or total bilirubin concentrations at baseline, then the dose would be delayed for grade 2 or worse adverse events; if these 
laboratory parameters were at grade 1 at baseline, the dose would be delayed for grade 3 or worse adverse events. Criteria for permanent treatment discontinuation include the following treatment-related adverse events: grade 2 uveitis, grade 3 non-skin events lasting 7 days or more, grade 3 laboratory abnormalities of thrombocytopenia or liver function test, and all grade 4 events, as well as laboratory abnormalities, except for asymptomatic amylase or lipase elevations.

Tumour assessments by radiographic imaging (CT and MRI) were done at baseline, every 6 weeks for the first 24 weeks, and every 12 weeks thereafter until disease progression (investigator-assessed per RECIST) or treatment discontinuation. Survival was monitored continuously while patients were on treatment and every 3 months after treatment discontinuation. Safety was evaluated throughout the study (appendix p 20), and adverse events were graded according to the National Cancer Institute's Common Terminology Criteria for Adverse Events (CTCAE), version 4.0.

Tumour PD-L1 protein expression was assessed retrospectively in pretreatment (archival or fresh) tumour biopsy specimens with the use of a validated, automated immunohistochemical assay (Dako North America, Carpinteria, CA, USA) using a rabbit anti-human PD-L1 antibody (clone 28-8; Epitomics Inc, Burlingame, CA, USA). ${ }^{23}$ Tumour PD-L1 expression was categorised as positive when staining of tumour-cell membranes (at any intensity) was observed at prespecified expression levels ( $\geq 1 \%$ or $\geq 5 \%$ of tumour cells in a section that included $\geq 100$ evaluable tumour cells). In the initial study protocol, analysis of the specimen was not required in advance of patient allocation; the protocol was later revised and this was made a requirement via a study amendment on Aug 6, 2015 (for all cohorts of the study).

\section{Outcomes}

The primary endpoint of this study was the proportion of patients with a confirmed objective response (defined as the number of patients with a best overall response of complete response or partial response as per investigatorassessed RECIST divided by the number of assigned patients). Objective response was the primary endpoint because the trial objective was to evaluate antitumour activity of nivolumab alone or in combination with ipilimumab.

The secondary endpoints included overall survival, progression-free survival, duration of response, and the occurrence of treatment-related adverse events leading to treatment discontinuation. Overall survival was defined as the time between the date of treatment assignment and the date of death due to any cause. Progression-free survival was defined as the time from treatment assignment to the date of the first documented tumour progression, as determined by the investigator, or death due to any cause, whichever occurred first. Duration of response was defined as the time from a best overall response of partial or complete response until the date progressive disease was documented or death due to any cause. The correlation between PD-L1 expression by tumour cells and antitumour activity was a prespecified exploratory endpoint.

\section{Statistical analysis}

In parallel to the safety evaluation phase for the combination arms, enrolment of patients followed a Simon two-stage design. ${ }^{24}$ Stage 1 of the study was intended to assess the efficacy of nivolumab and ipilimumab in 18 patients per treatment group, to determine whether enrolment should continue to stage 2 . However, enrolment and treatment of 18 individuals in the nivolumab monotherapy group could begin while the initial dose cohort of the combination cohorts was ongoing. This design was used to test whether nivolumab, or the combination of nivolumab and ipilimumab, or both, yielded an objective response in a sufficient proportion of patients to be of clinical interest in each of the tumour types; it also limited the expected number of patients who would receive treatment if the true proportion of patients achieving a response was not of clinical value. The two-stage test was conducted independently in each treatment cohort.

For each treatment cohort, the modified Simon design required 18 treated patients for the first stage and called for termination at this stage if only one patient or no patients in the cohort had a confirmed partial or complete response. If two or more patients responded in the first stage, additional patients were assigned in stage 2 , to a total of 40 treated patients in that cohort. The treatment was considered of clinical interest if, at the end of the second stage, there were eight or more patients with a response among 40 treated patients. Enrolment in stage 2 in a particular treatment cohort could continue even if the other treatment cohorts were still in stage 1 . The modified Simon design tested the null hypothesis that the true proportion of patients achieving a response was $\leq 10 \%$ versus the alternative hypothesis that the true proportion of patients achieving a response was $>10 \%$. The two-stage testing within each cohort targeted a type I error rate of $5 \%$ and had $80 \%$ power to reject the null hypothesis if the true proportion of patients achieving a response was $25 \%$. The tests did not adjust for multiplicity across the cohorts.

For stage 2, after completion of enrolment for the initial 40 patients, additional patients could be assigned into the nivolumab monotherapy and combination cohorts up to a total of 100 patients in each cohort (including those assigned in stage 1 ). When nivolumab $3 \mathrm{mg} / \mathrm{kg}$ or nivolumab $1 \mathrm{mg} / \mathrm{kg}$ plus ipilimumab $3 \mathrm{mg} / \mathrm{kg}$ proceeded to stage 2 , assessment of dose level $2 \mathrm{~b}$ in stage 2 (nivolumab $3 \mathrm{mg} / \mathrm{kg}$ plus ipilimumab $1 \mathrm{mg} / \mathrm{kg}$ ) was initiated. If all prespecified safety and efficacy criteria to proceed to stage 2 were met for each tumour type and treatment group, those regimens were continued. 
The date of the database lock for all activity and safety data (except overall survival) was Nov 6, 2015. The date of database lock for overall survival data was March 24, 2016. All analyses included treated patients who were enrolled at least 90 days before database lock. All activity analyses were performed on the basis of the original treatment assignment, not by crossover status.

Objective response was summarised by a binomial response rate and corresponding two-sided 95\% exact CIs using the Clopper-Pearson method. Progression-free survival and overall survival were summarised descriptively using the Kaplan-Meier method; median values were estimated with two-sided $95 \%$ CIs, calculated using the Brookmeyer-Crowley method. Only treatment cohorts with more than six patients are represented in Kaplan-Meier plots. Patients with less than 12 weeks of follow-up were excluded from Kaplan-Meier plots. Progression-free survival and overall survival were also estimated with two-sided 95\% CIs, calculated using the Greenwood formula. Duration of response was summarised using the Kaplan-Meier product-limit method. For PD-L1 biomarker analysis, best overall response was summarised for each cohort by baseline PD-L1 expression and objective response, with exact 95\% CIs computed using the Clopper-Pearson method. All statistical analyses were done with SAS software (version 9.02).
This study is registered with ClinicalTrials.gov, number NCT01928394.

\section{Role of the funding source}

The funder provided the study drug and worked with the investigators to design the study, and to collect, analyse, and interpret the data. All drafts of the report were prepared by the corresponding author with input from all coauthors and editorial assistance from professional medical writers, funded by the sponsor. Raw data were made accessible to the authors and professional medical writers. All authors made the decision to submit the report for publication.

\section{Results}

We enrolled and treated 216 patients with SCLC between Nov 18, 2013, and July 28, 2015: 98 patients in the nivolumab $3 \mathrm{mg} / \mathrm{kg}$ cohort, three patients in the nivolumab $1 \mathrm{mg} / \mathrm{kg}$ plus ipilimumab $1 \mathrm{mg} / \mathrm{kg}$ cohort, 61 patients in the nivolumab $1 \mathrm{mg} / \mathrm{kg}$ plus ipilimumab $3 \mathrm{mg} / \mathrm{kg}$ cohort, and 54 in the nivolumab $3 \mathrm{mg} / \mathrm{kg}$ plus ipilimumab $1 \mathrm{mg} / \mathrm{kg}$ cohort (figure 1). Three patients in the nivolumab $3 \mathrm{mg} / \mathrm{kg}$ group, two patients in the nivolumab $1 \mathrm{mg} / \mathrm{kg}$ plus ipilimumab $3 \mathrm{mg} / \mathrm{kg}$ group, and four patients in the nivolumab $3 \mathrm{mg} / \mathrm{kg}$ plus ipilimumab $1 \mathrm{mg} / \mathrm{kg}$ group did not receive first-line

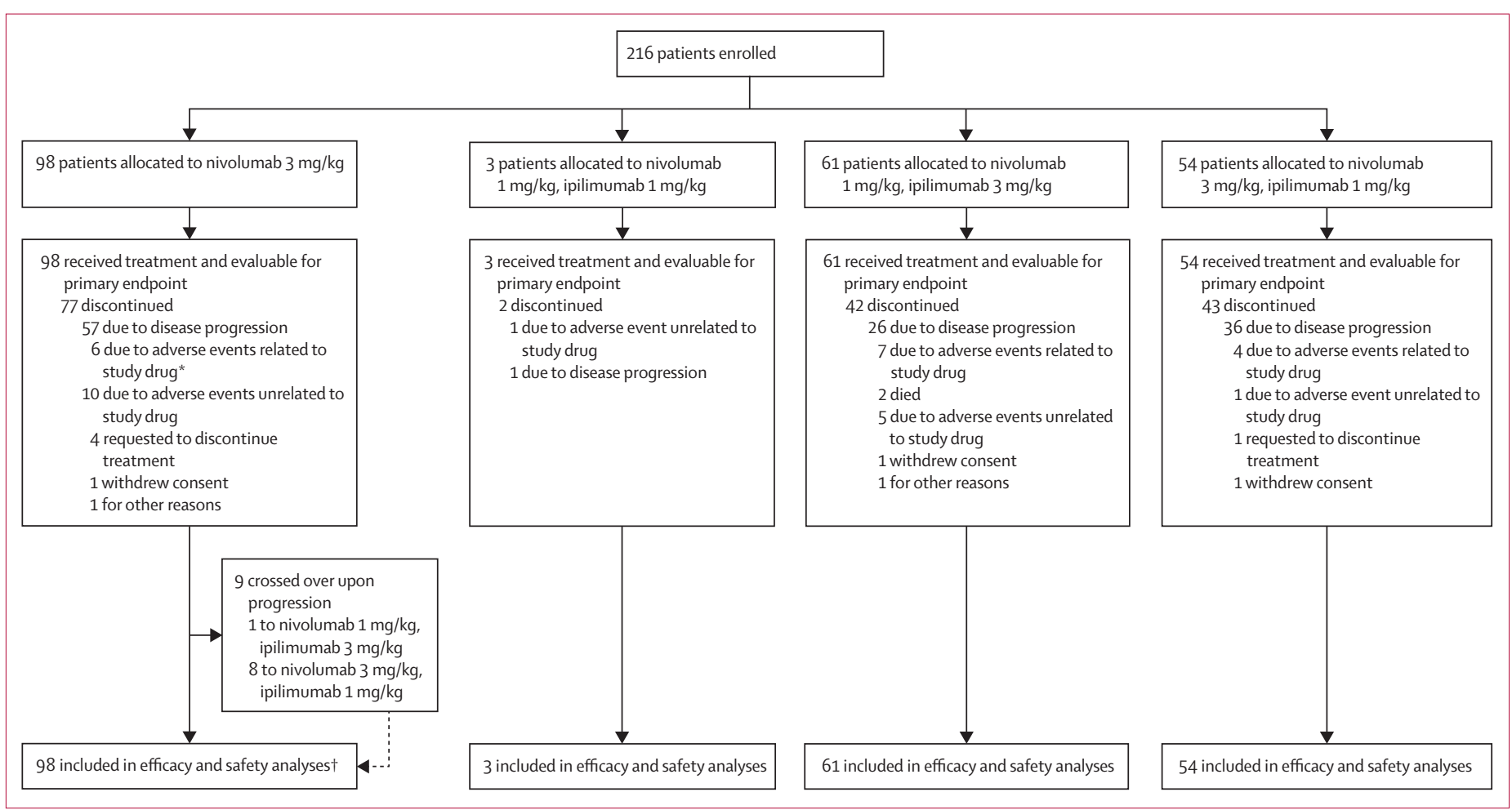

Figure 1: Study design

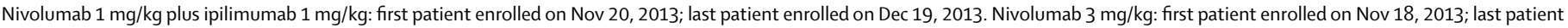
enrolled on July 28,2015 . Nivolumab $1 \mathrm{mg} / \mathrm{kg}$ plus ipilimumab $3 \mathrm{mg} / \mathrm{kg}$ : first patient enrolled on Feb 3, 2014; last patient enrolled on July 17,2015 . Nivolumab $3 \mathrm{mg} / \mathrm{kg}$ plus ipilimumab $1 \mathrm{mg} / \mathrm{kg}$ : first patient enrolled on Oct 20, 2014; last patient enrolled on April 9, 2015. Data are based on a Nov 6, 2015, database lock. *Including one patient with disease progression and one patient who requested to discontinue treatment. $†$ Not including adverse events in patients who received combination therapies after crossover. 
platinum therapy and did not meet eligibility criteria, but received treatment. None of the three patients in the nivolumab $1 \mathrm{mg} / \mathrm{kg}$ plus ipilimumab $1 \mathrm{mg} / \mathrm{kg}$ cohort permanently discontinued due to treatment-related adverse events within the first 6 weeks, allowing for enrolment in the other two combination cohorts: nivolumab $1 \mathrm{mg} / \mathrm{kg}$ plus ipilimumab $3 \mathrm{mg} / \mathrm{kg}$, and nivolumab $3 \mathrm{mg} / \mathrm{kg}$ plus ipilimumab $1 \mathrm{mg} / \mathrm{kg}$. At database lock, all patients had at least 12 weeks of follow-up; median follow-up for patients continuing in the study (including those who had died or discontinued treatment) was 198.5 days (IQR 163.0-464.0) in the nivolumab $3 \mathrm{mg} / \mathrm{kg}$ cohort, 302 days (IQR not calculable) in the nivolumab $1 \mathrm{mg} / \mathrm{kg}$ plus ipilimumab $1 \mathrm{mg} / \mathrm{kg}$ cohort, 361.0 days $(273 \cdot 0-470.0)$ in the nivolumab $1 \mathrm{mg} / \mathrm{kg}$ plus ipilimumab $3 \mathrm{mg} / \mathrm{kg}$ cohort, and $260 \cdot 5$ days

\begin{tabular}{|c|c|c|c|}
\hline & $\begin{array}{l}\text { Nivolumab } \\
3 \mathrm{mg} / \mathrm{kg}(\mathrm{n}=98)\end{array}$ & $\begin{array}{l}\text { Nivolumab } 1 \mathrm{mg} / \mathrm{kg} \\
\text { plus ipilimumab } \\
3 \mathrm{mg} / \mathrm{kg}(\mathrm{n}=61)\end{array}$ & $\begin{array}{l}\text { Nivolumab } \\
3 \mathrm{mg} / \mathrm{kg} \text { plus } \\
\text { ipilimumab } \\
1 \mathrm{mg} / \mathrm{kg}(\mathrm{n}=54)\end{array}$ \\
\hline Median age (years) & $63(57-68)$ & $66(58-71)$ & $61(56-65)$ \\
\hline Age $\geq 75$ years & $9(9 \%)$ & $7(11 \%)$ & 0 \\
\hline \multicolumn{4}{|l|}{ Sex } \\
\hline Male & $61(62 \%)$ & $35(57 \%)$ & $32(59 \%)$ \\
\hline Female & $37(38 \%)$ & $26(43 \%)$ & $22(41 \%)$ \\
\hline \multicolumn{4}{|l|}{ Race } \\
\hline White & $91(93 \%)$ & $60(98 \%)$ & $52(96 \%)$ \\
\hline Black or African American & $3(3 \%)$ & $1(2 \%)$ & 0 \\
\hline Other & $4(4 \%)$ & 0 & $1(2 \%)$ \\
\hline Not reported & 0 & 0 & $1(2 \%)$ \\
\hline \multicolumn{4}{|l|}{ Previous treatment regimens } \\
\hline 1 & $40(41 \%)$ & $32(52 \%)$ & $23(43 \%)$ \\
\hline $2-3$ & $55(56 \%)$ & $23(38 \%)$ & $28(52 \%)$ \\
\hline$>3$ & $3(3 \%)$ & $6(10 \%)$ & $3(6 \%)$ \\
\hline \multicolumn{4}{|l|}{ First-line platinum-treated patients* } \\
\hline Platinum-sensitive & $55(56 \%)$ & $25(41 \%)$ & $21(39 \%)$ \\
\hline Platinum-resistant $\dagger$ & $30(31 \%)$ & $23(38 \%)$ & $21(39 \%)$ \\
\hline Unknown & $10(10 \%)$ & $11(18 \%)$ & $8(15 \%)$ \\
\hline \multicolumn{4}{|l|}{ Smoking status } \\
\hline Current or former smoker & $95(97 \%)$ & $57(93 \%)$ & $48(89 \%)$ \\
\hline Never smoked & $3(3 \%)$ & $4(7 \%)$ & $5(9 \%)$ \\
\hline Unknown & 0 & 0 & $1(2 \%)$ \\
\hline \multicolumn{4}{|l|}{ PD-L1 expression levelł } \\
\hline$\geq 1 \%$ & $10(14 \%)$ & $9(24 \%)$ & $5(13 \%)$ \\
\hline$<1 \%$ & $59(86 \%)$ & $28(76 \%)$ & $35(88 \%)$ \\
\hline$\geq 5 \%$ & $4(6 \%)$ & $2(5 \%)$ & $1(3 \%)$ \\
\hline$<5 \%$ & $65(94 \%)$ & $35(95 \%)$ & $39(98 \%)$ \\
\hline $\begin{array}{l}\text { Indeterminate, not evaluable, or } \\
\text { missing }\end{array}$ & $29(30 \%)$ & $24(39 \%)$ & $14(26 \%)$ \\
\hline \multicolumn{4}{|c|}{$\begin{array}{l}\text { Data presented as n (\%) or median (IQR) unless otherwise stated. *Three patients in the nivolumab } 3 \mathrm{mg} / \mathrm{kg} \text { group, } \\
\text { two patients in the nivolumab } 1 \mathrm{mg} / \mathrm{kg} \text { plus ipilimumab } 3 \mathrm{mg} / \mathrm{kg} \text { group, and four patients in the nivolumab } 3 \mathrm{mg} / \mathrm{kg} \\
\text { plus ipilimumab } 1 \mathrm{mg} / \mathrm{kg} \text { group did not receive first-line platinum therapy and did not meet eligibility criteria, } \\
\text { although they were treated and included in the analysis. †Defined as a patient who relapsed < } 90 \text { days after } \\
\text { chemotherapy. } \text { Percentage of PD-L1 evaluable patients; may exceed } 100 \% \text { due to rounding. }\end{array}$} \\
\hline
\end{tabular}

$(248 \cdot 0-288 \cdot 0)$ in the nivolumab $3 \mathrm{mg} / \mathrm{kg}$ plus ipilimumab $1 \mathrm{mg} / \mathrm{kg}$ cohort (appendix p 24). Median follow-up for the overall survival data is shown in the appendix (p 24). Baseline characteristics are shown in table 1 and the appendix ( $p$ 21); roughly half of patients had been treated with two or more previous regimens, and about a third had platinum-resistant disease.

Patients received a median of 3.5 infusions of nivolumab (IQR 2.0-6.0) in the nivolumab $3 \mathrm{mg} / \mathrm{kg}$ cohort, 9.0 infusions of nivolumab (IQR not calculable) and 4.0 infusions of ipilimumab (IQR not calculable) in the nivolumab $1 \mathrm{mg} / \mathrm{kg}$ plus ipilimumab $1 \mathrm{mg} / \mathrm{kg}$ cohort, $3 \cdot 0$ infusions each of nivolumab $(2 \cdot 0-14 \cdot 0)$ and ipilimumab $(2 \cdot 0-4 \cdot 0)$ in the nivolumab $1 \mathrm{mg} / \mathrm{kg}$ plus ipilimumab $3 \mathrm{mg} / \mathrm{kg}$ cohort, and 2.0 infusions each of nivolumab $(2 \cdot 0-6 \cdot 0)$ and ipilimumab $(2 \cdot 0-4 \cdot 0)$ in the nivolumab $3 \mathrm{mg} / \mathrm{kg}$ plus ipilimumab $1 \mathrm{mg} / \mathrm{kg}$ cohort. At the time of analysis, 77 (79\%) patients had discontinued nivolumab $3 \mathrm{mg} / \mathrm{kg}, 42$ (69\%) had discontinued nivolumab $1 \mathrm{mg} / \mathrm{kg}$ plus ipilimumab $3 \mathrm{mg} / \mathrm{kg}$, and $43(80 \%)$ had discontinued nivolumab $3 \mathrm{mg} / \mathrm{kg}$ plus ipilimumab $1 \mathrm{mg} / \mathrm{kg}$; the most common reason was disease progression (figure 1; appendix $\mathrm{p} 24$ ). Two patients discontinued nivolumab $1 \mathrm{mg} / \mathrm{kg}$ plus ipilimumab $1 \mathrm{mg} / \mathrm{kg}$ (one due to disease progression, and one due to adverse event not related to study drug).

By investigator-assessed RECIST, ten $(10 \%$ [95\% CI 5-18]) of 98 patients achieved a confirmed objective response with nivolumab $3 \mathrm{mg} / \mathrm{kg}, 14$ (23\% [13-36]) of 61 with nivolumab $1 \mathrm{mg} / \mathrm{kg}$ plus ipilimumab $3 \mathrm{mg} / \mathrm{kg}$, and ten (19\% [9-31]) of 54 with nivolumab $3 \mathrm{mg} / \mathrm{kg}$ plus ipilimumab $1 \mathrm{mg} / \mathrm{kg}$ (table 2; figure 2). One $(33 \%)$ of three patients receiving nivolumab $1 \mathrm{mg} / \mathrm{kg}$ plus ipilimumab $1 \mathrm{mg} / \mathrm{kg}$ achieved an objective response (appendix p 22). The predefined threshold that two or more of 18 patients in a particular group must have confirmed partial or complete response before continued enrolment for that group in stage 2 was met. In the nivolumab $3 \mathrm{mg} / \mathrm{kg}$ cohort, seven patients died before disease assessment, four patients discontinued early (one due to toxicity, three due to clinical progression), and one patient withdrew consent before completing the protocol; in the nivolumab $1 \mathrm{mg} / \mathrm{kg}$ plus ipilimumab $3 \mathrm{mg} / \mathrm{kg}$ cohort, five patients died before disease assessment, one patient discontinued early due to clinical progression, one patient was not evaluable because the first assessment was not performed, and one patient withdrew consent for scans and follow-up visits; and in the nivolumab $3 \mathrm{mg} / \mathrm{kg}$ plus ipilimumab $1 \mathrm{mg} / \mathrm{kg}$ cohort, two patients died before disease assessment, three patients discontinued early (two due to clinical progression and one due to toxicity), and a CT scan was not performed on one patient. The median duration of response was not reached ( $95 \%$ CI 4.4 not reached) with nivolumab $3 \mathrm{mg} / \mathrm{kg}, 7.7$ months (4.0-not reached) with nivolumab $1 \mathrm{mg} / \mathrm{kg}$ plus ipilimumab $3 \mathrm{mg} / \mathrm{kg}$, and 4.4 months (3.7-not reached) with nivolumab $3 \mathrm{mg} / \mathrm{kg}$ 
plus ipilimumab $1 \mathrm{mg} / \mathrm{kg} .16$ patients had a duration of response longer than 6 months: six patients in the nivolumab $3 \mathrm{mg} / \mathrm{kg}$ group, one patient in the nivolumab $1 \mathrm{mg} / \mathrm{kg}$ plus ipilimumab $1 \mathrm{mg} / \mathrm{kg}$ group, eight patients in the nivolumab $1 \mathrm{mg} / \mathrm{kg}$ plus ipilimumab $3 \mathrm{mg} / \mathrm{kg}$ group, and one patient in the nivolumab $3 \mathrm{mg} / \mathrm{kg}$ plus ipilimumab $1 \mathrm{mg} / \mathrm{kg}$ group (median 9.6 months [IQR 7·1-14.3]). Median time to response is shown in table 2. Tumour response data in the nivolumab $1 \mathrm{mg} / \mathrm{kg}$ plus ipilimumab $1 \mathrm{mg} / \mathrm{kg}$ cohort are shown in the appendix (p 22). At the time of database lock, eight (80\%) of ten responses in the nivolumab $3 \mathrm{mg} / \mathrm{kg}$ group, one of three responses in the nivolumab $1 \mathrm{mg} / \mathrm{kg}$ plus ipilimumab $1 \mathrm{mg} / \mathrm{kg}$ group, seven (50\%) of 14 responses in the nivolumab $1 \mathrm{mg} / \mathrm{kg}$ plus ipilimumab $3 \mathrm{mg} / \mathrm{kg}$ group, and seven (70\%) of ten responses in the nivolumab $3 \mathrm{mg} / \mathrm{kg}$ plus ipilimumab $1 \mathrm{mg} / \mathrm{kg}$ group were ongoing. 30 patients in the nivolumab $3 \mathrm{mg} / \mathrm{kg}$ cohort, 15 in the nivolumab $1 \mathrm{mg} / \mathrm{kg}$ plus ipilimumab $3 \mathrm{mg} / \mathrm{kg}$ cohort, and six in the nivolumab $3 \mathrm{mg} / \mathrm{kg}$ plus ipilimumab $1 \mathrm{mg} / \mathrm{kg}$ cohort continued treatment beyond progression.

As of the database lock on March 24, 2016, 60 (61\%) of 98 patients in the nivolumab $3 \mathrm{mg} / \mathrm{kg}$ cohort, 36 (59\%) of 61 in the nivolumab $1 \mathrm{mg} / \mathrm{kg}$ plus ipilimumab $3 \mathrm{mg} / \mathrm{kg}$, and $35(64 \%)$ of 55 in the nivolumab $3 \mathrm{mg} / \mathrm{kg}$ plus ipilimumab $1 \mathrm{mg} / \mathrm{kg}$ had died. Median overall survival was 4.4 months $(95 \%$ CI $3 \cdot 0-9 \cdot 3)$ in the nivolumab $3 \mathrm{mg} / \mathrm{kg}$ cohort, $7 \cdot 7$ months $(3 \cdot 6-18 \cdot 0)$ in the nivolumab $1 \mathrm{mg} / \mathrm{kg}$ plus ipilimumab $3 \mathrm{mg} / \mathrm{kg}$ cohort, and $6 \cdot 0$ months $(3 \cdot 6-11 \cdot 0)$ in the nivolumab $3 \mathrm{mg} / \mathrm{kg}$ plus ipilimumab $1 \mathrm{mg} / \mathrm{kg}$ cohort. 1-year overall survival was $33 \%$ (95\% CI 22-45) for the nivolumab $3 \mathrm{mg} / \mathrm{kg}$ cohort, $43 \%$ (30-56) for the nivolumab $1 \mathrm{mg} / \mathrm{kg}$ plus ipilimumab $3 \mathrm{mg} / \mathrm{kg}$ cohort, and 35\% (22-48) for the nivolumab $3 \mathrm{mg} / \mathrm{g}$ plus ipilimumab $1 \mathrm{mg} / \mathrm{kg}$ cohort (figure 3A).

\begin{tabular}{|c|c|c|c|}
\hline & $\begin{array}{l}\text { Nivolumab } \\
3 \mathrm{mg} / \mathrm{kg} \\
(\mathrm{n}=98)\end{array}$ & $\begin{array}{l}\text { Nivolumab } \\
1 \mathrm{mg} / \mathrm{kg} \text { plus } \\
\text { ipilimumab } \\
3 \mathrm{mg} / \mathrm{kg} \\
(\mathrm{n}=61)\end{array}$ & $\begin{array}{l}\text { Nivolumab } \\
3 \mathrm{mg} / \mathrm{kg} \text { plus } \\
\text { ipilimumab } \\
1 \mathrm{mg} / \mathrm{kg} \\
(\mathrm{n}=54)\end{array}$ \\
\hline $\begin{array}{l}\text { Objective response; } \\
95 \% \mathrm{Cl}\end{array}$ & $10(10 \% ; 5-18)$ & $14(23 \% ; 13-36)$ & 10 (19\%; 9-31) \\
\hline \multicolumn{4}{|l|}{ Best overall response } \\
\hline Complete response & 0 & $1(2 \%)$ & 0 \\
\hline Partial response & $10(10 \%)$ & $13(21 \%)$ & $10(19 \%)$ \\
\hline Stable disease & $22(22 \%)$ & $13(21 \%)$ & $9(17 \%)$ \\
\hline Progressive disease & $52(53 \%)$ & $23(38 \%)$ & $29(54 \%)$ \\
\hline Unable to determine & $12(12 \%)$ & $8(13 \%)$ & $6(11 \%)$ \\
\hline Not reported & $2(2 \%)$ & $3(5 \%)$ & 0 \\
\hline $\begin{array}{l}\text { Time to objective } \\
\text { response (IQR), } \\
\text { months }\end{array}$ & $2 \cdot 0(1 \cdot 3-2 \cdot 8)$ & $2 \cdot 1(1 \cdot 4-2 \cdot 8)$ & $1 \cdot 4(1 \cdot 3-2 \cdot 7)$ \\
\hline \multicolumn{4}{|c|}{$\begin{array}{l}\text { Data are } n(\%) \text { unless otherwise stated. All patients were enrolled at least } 90 \text { days } \\
\text { prior to database lock. }\end{array}$} \\
\hline
\end{tabular}

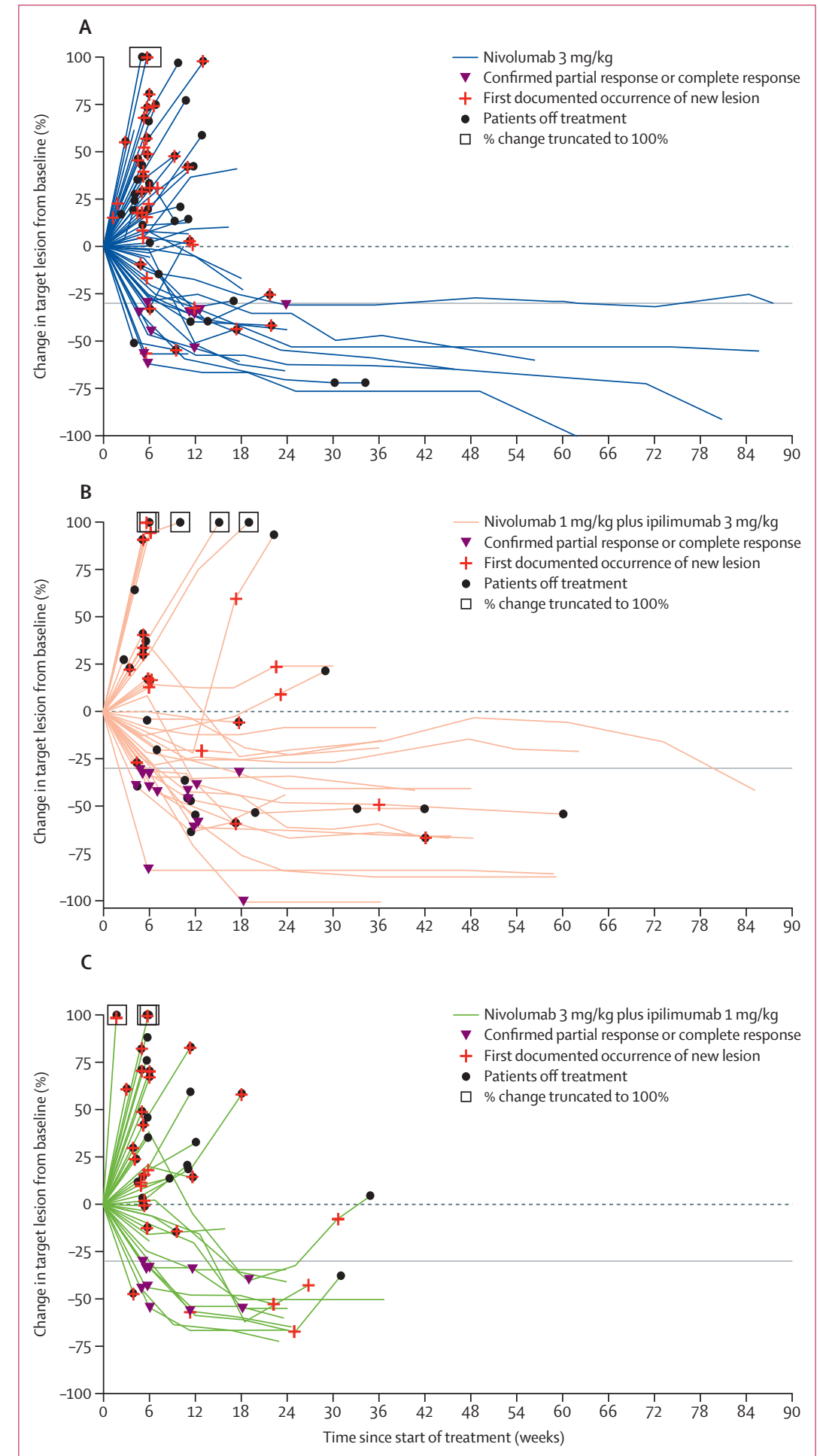

Figure 2: Changes in tumour burden in individual patients

Tumour burden (assessed as the longest linear dimension) in patients receiving nivolumab $3 \mathrm{mg} / \mathrm{kg}(\mathrm{A})$, nivolumab $1 \mathrm{mg} / \mathrm{kg}$ plus ipilimumab $3 \mathrm{mg} / \mathrm{kg}$ (B), and nivolumab $3 \mathrm{mg} / \mathrm{kg}$ plus ipilimumab $1 \mathrm{mg} / \mathrm{kg}$ (C)

Only patients with target lesions at baseline and with at least one on-treatment tumour assessment were included (nivolumab $3 \mathrm{mg} / \mathrm{kg}, \mathrm{n}=80$; nivolumab $1 \mathrm{mg} / \mathrm{kg}$ plus ipilimumab $3 \mathrm{mg} / \mathrm{kg}, \mathrm{n}=46$; nivolumab $3 \mathrm{mg} / \mathrm{kg}$ plus ipilimumab $1 \mathrm{mg} / \mathrm{kg}, \mathrm{n}=47$ ). Horizontal grey line indicates the $30 \%$ reduction consistent with a RECIST (version 1.1) objective response. RECIST=Response Evaluation Criteria in Solid Tumors. 
$76(78 \%)$ patients in the nivolumab $3 \mathrm{mg} / \mathrm{kg}$ cohort, $44(72 \%)$ in the nivolumab $1 \mathrm{mg} / \mathrm{kg}$ plus ipilimumab $3 \mathrm{mg} / \mathrm{kg}$ cohort, and 42 (78\%) in the nivolumab $3 \mathrm{mg} / \mathrm{kg}$ plus ipilimumab $1 \mathrm{mg} / \mathrm{kg}$ cohort had disease progression or died; median progression-free survival was 1.4 months (95\% CI 1.4-1.9), 2.6 months (1.4-4.1), and 1.4 months $(1 \cdot 3-2 \cdot 2)$, respectively. 1-year progression-free survival was $11 \%$ (95\% CI 5-19) in the nivolumab $3 \mathrm{mg} / \mathrm{kg}$ cohort and 19\% (9-32) for the

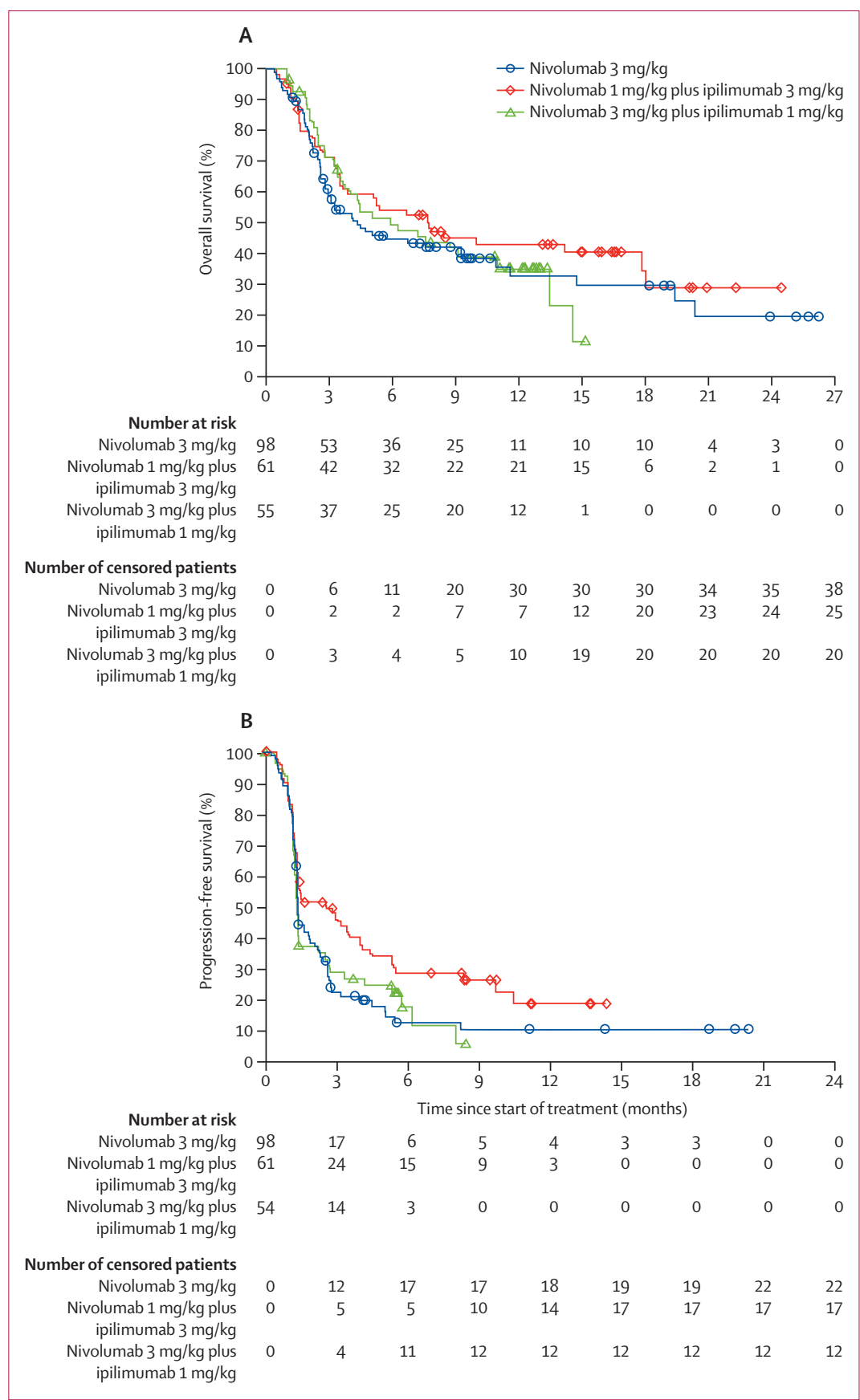

Figure 3: Kaplan-Meier curves of overall survival (A) and progression-free survival (B) nivolumab $1 \mathrm{mg} / \mathrm{kg}$ plus ipilimumab $3 \mathrm{mg} / \mathrm{kg}$ cohort (figure $3 \mathrm{~B}$ ). The nivolumab $3 \mathrm{mg} / \mathrm{kg}$ plus ipilimumab $1 \mathrm{mg} / \mathrm{kg}$ cohort had not met the 1-year milestone for progression-free survival at the time of database lock. Two (67\%) of three patients in the nivolumab $1 \mathrm{mg} / \mathrm{kg}$ plus ipilimumab $1 \mathrm{mg} / \mathrm{kg}$ cohort had died and one (33\%) had a progression event. Nine patients crossed over from the nivolumab $3 \mathrm{mg} / \mathrm{kg}$ cohort to the combination cohorts after progression (one to nivolumab $1 \mathrm{mg} / \mathrm{kg}$ plus ipilimumab $3 \mathrm{mg} / \mathrm{kg}$ and eight to nivolumab $3 \mathrm{mg} / \mathrm{kg}$ plus ipilimumab $1 \mathrm{mg} / \mathrm{kg}$ ); eight of these patients had further disease progression and one patient in the nivolumab $3 \mathrm{mg} / \mathrm{kg}$ plus ipilimumab $1 \mathrm{mg} / \mathrm{kg}$ cohort withdrew consent and therefore response could not be determined.

PD-L1 expression was assessable in 148 (69\%) of 216 patient samples, of which 39 (27\%) were provided as fresh biopsies and 109 (74\%) were archived specimens. $25(17 \%)$ had $1 \%$ or greater PD-L1 expression, and seven $(5 \%)$ had $5 \%$ or greater PD-L1 expression (table 1; appendix p 21). In a pre-planned exploratory analysis of the nivolumab $3 \mathrm{mg} / \mathrm{kg}$, nivolumab $1 \mathrm{mg} / \mathrm{kg}$ plus ipilimumab $3 \mathrm{mg} / \mathrm{kg}$, and nivolumab $3 \mathrm{mg} / \mathrm{kg}$ plus ipilimumab $1 \mathrm{mg} / \mathrm{kg}$ cohorts, tumour responses occurred in patients irrespective of PD-L1 expression (appendix pp 15-18).

Grade 3 or 4 treatment-related adverse events occurred in $13(13 \%)$ of 98 patients in the nivolumab $3 \mathrm{mg} / \mathrm{kg}$ cohort, 18 (30\%) of 61 patients in the nivolumab $1 \mathrm{mg} / \mathrm{kg}$ plus ipilimumab $3 \mathrm{mg} / \mathrm{kg}$ cohort, and ten (19\%) of 54 patients in the nivolumab $3 \mathrm{mg} / \mathrm{kg}$ plus ipilimumab $1 \mathrm{mg} / \mathrm{kg}$ cohort (table 3); no patients in the nivolumab $1 \mathrm{mg} / \mathrm{kg}$ plus ipilimumab $1 \mathrm{mg} / \mathrm{kg}$ cohort had a grade 3 or 4 treatment-related adverse event (appendix p 23). The most commonly reported grade 3 or 4 treatmentrelated adverse events were increased lipase (none vs 5 [8\%] vs none) and diarrhoea (none vs 3 [5\%] vs 1 [2\%]). Four (4\%) patients in the nivolumab $3 \mathrm{mg} / \mathrm{kg}$ cohort two $(67 \%)$ in the nivolumab $1 \mathrm{mg} / \mathrm{kg}$ plus ipilimumab $1 \mathrm{mg} / \mathrm{kg}$ cohort, 18 (30\%) in the nivolumab $1 \mathrm{mg} / \mathrm{kg}$ plus ipilimumab $3 \mathrm{mg} / \mathrm{kg}$ cohort, and eight (15\%) in the nivolumab $3 \mathrm{mg} / \mathrm{kg}$ plus ipilimumab $1 \mathrm{mg} / \mathrm{kg}$ cohort had dose delays due to treatment-related adverse events (appendix p 26). All-causality adverse events and serious adverse events are shown in the appendix (pp 27-30). Excluding malignant neoplasm, the most frequent serious adverse events were dyspnoea, experienced by five (5\%) patients in the nivolumab $3 \mathrm{mg} / \mathrm{kg}$ cohort, two $(3 \%)$ in the nivolumab $1 \mathrm{mg} / \mathrm{kg}$ plus ipilimumab $3 \mathrm{mg} / \mathrm{kg}$ cohort, and four (7\%) in the nivolumab $3 \mathrm{mg} / \mathrm{kg}$ plus ipilimumab $1 \mathrm{mg} / \mathrm{kg}$ cohort, and diarrhoea experienced by two $(2 \%)$ patients in the nivolumab $3 \mathrm{mg} / \mathrm{kg}$ cohort, four (7\%) in the nivolumab $1 \mathrm{mg} / \mathrm{kg}$ plus ipilimumab $3 \mathrm{mg} / \mathrm{kg}$ cohort, and two (4\%) patients in the nivolumab $3 \mathrm{mg} / \mathrm{kg}$ plus ipilimumab $1 \mathrm{mg} / \mathrm{kg}$ cohort. 17 patients discontinued treatment because of treatment-related adverse events: six (6\%) patients in the 


\begin{tabular}{|c|c|c|c|c|c|c|c|c|c|}
\hline & \multicolumn{3}{|c|}{ Nivolumab 3 mg/kg ( $=98)$} & \multicolumn{3}{|c|}{$\begin{array}{l}\text { Nivolumab } 1 \mathrm{mg} / \mathrm{kg} \text { plus ipilimumab } \\
3 \mathrm{mg} / \mathrm{kg}(\mathrm{n}=61)\end{array}$} & \multicolumn{3}{|c|}{$\begin{array}{l}\text { Nivolumab } 3 \mathrm{mg} / \mathrm{kg} \text { plus ipilimumab } \\
1 \mathrm{mg} / \mathrm{kg}(\mathrm{n}=54)\end{array}$} \\
\hline & Grade 1-2 & Grade 3 & Grade 4 & Grade 1-2 & Grade 3 & Grade 4 & Grade 1-2 & Grade 3 & Grade 4 \\
\hline Any event & $39(40 \%)$ & $9(9 \%)$ & $4(4 \%)$ & $30(49 \%)$ & $14(23 \%)$ & $4(7 \%)$ & $30(56 \%)$ & $8(15 \%)$ & $2(4 \%)$ \\
\hline Fatigue & $10(10 \%)$ & $1(1 \%)$ & 0 & $16(26 \%)$ & 0 & 0 & $12(22 \%)$ & 0 & 0 \\
\hline Pruritus & $11(11 \%)$ & 0 & 0 & $11(18 \%)$ & $1(2 \%)$ & 0 & $5(9 \%)$ & 0 & 0 \\
\hline Diarrhoea & $7(7 \%)$ & 0 & 0 & $10(16 \%)$ & $3(5 \%)$ & 0 & $8(15 \%)$ & $1(2 \%)$ & 0 \\
\hline Nausea & $7(7 \%)$ & 0 & 0 & $6(10 \%)$ & $1(2 \%)$ & 0 & $4(7 \%)$ & 0 & 0 \\
\hline Decreased appetite & $6(6 \%)$ & 0 & 0 & $4(7 \%)$ & 0 & 0 & $6(11 \%)$ & 0 & 0 \\
\hline Pneumonitis & $2(2 \%)$ & $1(1 \%)$ & 0 & $1(2 \%)$ & $1(2 \%)$ & 0 & $2(4 \%)$ & 0 & $1(2 \%)$ \\
\hline Vomiting & $2(2 \%)$ & $1(1 \%)$ & 0 & $2(3 \%)$ & $1(2 \%)$ & 0 & $5(9 \%)$ & 0 & 0 \\
\hline Hypothyroidism & $3(3 \%)$ & 0 & 0 & $9(15 \%)$ & $1(2 \%)$ & 0 & $4(7 \%)$ & 0 & 0 \\
\hline $\begin{array}{l}\text { Increased aspartate } \\
\text { aminotransferase }\end{array}$ & $3(3 \%)$ & 0 & 0 & $3(5 \%)$ & 0 & 0 & 0 & $1(2 \%)$ & 0 \\
\hline Hyperthyroidism & $2(2 \%)$ & 0 & 0 & $7(11 \%)$ & 0 & 0 & $3(6 \%)$ & 0 & 0 \\
\hline Hyponatraemia & $2(2 \%)$ & 0 & 0 & 0 & $1(2 \%)$ & 0 & 0 & 0 & 0 \\
\hline $\begin{array}{l}\text { Increased alanine } \\
\text { aminotransferase }\end{array}$ & $2(2 \%)$ & $1(1 \%)$ & 0 & $2(3 \%)$ & 0 & 0 & 0 & $1(2 \%)$ & 0 \\
\hline Increased transaminases & $2(2 \%)$ & 0 & 0 & 0 & 0 & 0 & $1(2 \%)$ & $1(2 \%)$ & 0 \\
\hline Rash & $2(2 \%)$ & 0 & 0 & $10(16 \%)$ & $2(3 \%)$ & 0 & $4(7 \%)$ & 0 & 0 \\
\hline Anaemia & $1(1 \%)$ & 0 & 0 & $4(7 \%)$ & 0 & 0 & $3(6 \%)$ & $1(2 \%)$ & 0 \\
\hline Dyspnoea & $1(1 \%)$ & 0 & 0 & 0 & $1(2 \%)$ & 0 & $1(2 \%)$ & $2(4 \%)$ & 0 \\
\hline Rash, maculopapular & $1(1 \%)$ & 0 & 0 & $6(10 \%)$ & $2(3 \%)$ & 0 & $2(4 \%)$ & 0 & 0 \\
\hline Adrenal insufficiency & 0 & 0 & 0 & $1(2 \%)$ & 0 & 0 & $1(2 \%)$ & $1(2 \%)$ & 0 \\
\hline Aseptic meningitis & 0 & 0 & 0 & 0 & 0 & 0 & 0 & 0 & $1(2 \%)$ \\
\hline Cardiomyopathy & 0 & 0 & 0 & 0 & 0 & $1(2 \%)$ & 0 & 0 & 0 \\
\hline Colitis & 0 & 0 & 0 & $1(2 \%)$ & $1(2 \%)$ & 0 & 0 & $1(2 \%)$ & 0 \\
\hline Decreased neutrophil count & 0 & 0 & 0 & 0 & $1(2 \%)$ & 0 & 0 & 0 & 0 \\
\hline Drug-induced liver injury & 0 & $1(1 \%)$ & 0 & 0 & 0 & 0 & 0 & 0 & 0 \\
\hline Encephalitis & 0 & 0 & $1(1 \%)$ & $1(2 \%)$ & 0 & 0 & 0 & 0 & 0 \\
\hline Eyelid ptosis & 0 & 0 & 0 & 0 & $1(2 \%)$ & 0 & 0 & 0 & 0 \\
\hline Haemorrhagic gastritis & 0 & 0 & 0 & 0 & $1(2 \%)$ & 0 & 0 & 0 & 0 \\
\hline Hyperglycaemia & 0 & 0 & $1(1 \%)$ & $2(3 \%)$ & 0 & $1(2 \%)$ & 0 & 0 & 0 \\
\hline Hypertransaminasaemia & 0 & 0 & 0 & 0 & $1(2 \%)$ & 0 & 0 & 0 & 0 \\
\hline Hypoxia & 0 & $1(1 \%)$ & 0 & 0 & 0 & 0 & 0 & 0 & 0 \\
\hline Ileus & 0 & 0 & 0 & 0 & 0 & 0 & 0 & $1(2 \%)$ & 0 \\
\hline Increased amylase & 0 & 0 & $1(1 \%)$ & $3(5 \%)$ & $1(2 \%)$ & 0 & $2(4 \%)$ & 0 & 0 \\
\hline $\begin{array}{l}\text { Increased gamma } \\
\text { glutamyltransferase }\end{array}$ & 0 & 0 & $1(1 \%)$ & 0 & 0 & 0 & 0 & $1(2 \%)$ & 0 \\
\hline Increased lipase & 0 & 0 & 0 & $2(3 \%)$ & $4(7 \%)$ & $1(2 \%)$ & 0 & 0 & 0 \\
\hline Large intestine perforation & 0 & 0 & 0 & 0 & 0 & 0 & 0 & $1(2 \%)$ & 0 \\
\hline Myasthenia gravis & 0 & 0 & 0 & 0 & $1(2 \%)$ & 0 & 0 & 0 & 0 \\
\hline Non-cardiac chest pain & 0 & $1(1 \%)$ & 0 & 0 & 0 & 0 & 0 & 0 & 0 \\
\hline Pericardial effusion & 0 & $1(1 \%)$ & 0 & 0 & 0 & 0 & 0 & 0 & 0 \\
\hline Peripheral neuropathy & 0 & 0 & 0 & 0 & 0 & 0 & 0 & $1(2 \%)$ & 0 \\
\hline Renal failure & 0 & 0 & 0 & 0 & 0 & $1(2 \%)$ & 0 & 0 & 0 \\
\hline Stomatitis & 0 & $1(1 \%)$ & 0 & $1(2 \%)$ & 0 & 0 & 0 & 0 & 0 \\
\hline Thrombocytopenia & 0 & 0 & 0 & 0 & 0 & 0 & $3(6 \%)$ & $1(2 \%)$ & 0 \\
\hline Tumour lysis syndrome & 0 & 0 & 0 & 0 & 0 & 0 & 0 & $1(2 \%)$ & 0 \\
\hline \multicolumn{10}{|c|}{$\begin{array}{l}\text { Data presented as } \mathrm{n}(\%) \text {.This table reports grade } 1-2 \text { treatment-related events in } \geq 10 \% \text { of patients in any treatment cohort and all grade } 3-4 \text { events. Safety analyses include } \\
\text { all patients who were enrolled at least } 90 \text { days prior to database lock; patients with adverse events after crossover from nivolumab } 3 \mathrm{mg} / \mathrm{kg} \text { to combination treatment are } \\
\text { excluded. Some patients had more than one adverse event. Two patients in the nivolumab } 1 \mathrm{mg} / \mathrm{kg} \text { plus ipilimumab } 3 \mathrm{mg} / \mathrm{kg} \text { group died from myasthenia gravis and } \\
\text { worsening of renal failure, respectively; both events were regarded to be treatment related. One patient in the nivolumab } 3 \mathrm{mg} / \mathrm{kg} \text { plus ipilimumab } 1 \mathrm{mg} / \mathrm{kg} \text { cohort died fro } \\
\text { pneumonitis, regarded as treatment related. All-causality adverse events and serious adverse events are shown in the appendix (pp 27-30). }\end{array}$} \\
\hline
\end{tabular}


nivolumab $3 \mathrm{mg} / \mathrm{kg}$ cohort (one patient each with limbic encephalitis, hyperglycaemia, stomatitis, increased alanine aminotransferase, increased gamma glutamyltransferase, and pneumonitis), seven (11\%) in the nivolumab $1 \mathrm{mg} / \mathrm{kg}$ plus ipilimumab $3 \mathrm{mg} / \mathrm{kg}$ cohort (one patient each with colitis, myasthenia gravis, pneumonitis, and cardiomyopathy, and uveitis; one patient with hypothyroidism and hyperglycaemia; one patient with diarrhoea and renal failure), and four (7\%) in the nivolumab $3 \mathrm{mg} / \mathrm{kg}$ plus ipilimumab $1 \mathrm{mg} / \mathrm{kg}$ cohort (one patient each with colitis, pneumonitis, and peripheral neuropathy; one patient with dyspnoea and pneumonitis; table 3; appendix p 31). Two patients who received nivolumab $1 \mathrm{mg} / \mathrm{kg}$ plus ipilimumab $3 \mathrm{mg} / \mathrm{kg}$ died from treatment-related events of myasthenia gravis $^{25}$ and worsening of renal failure, respectively, and one patient who received nivolumab $3 \mathrm{mg} / \mathrm{kg}$ plus ipilimumab $1 \mathrm{mg} / \mathrm{kg}$ died from treatment-related pneumonitis (appendix $\mathrm{p}$ 4). Other than because of disease progression and study drug toxicity, the following deaths were reported: in the nivolumab $3 \mathrm{mg} / \mathrm{kg}$ group, three $(3 \%)$ due to unknown causes, one $(1 \%)$ due to sepsis and multiorgan failure, and one (1\%) due to respiratory insufficiency not related to treatment; in the nivolumab $1 \mathrm{mg} / \mathrm{kg}$ plus ipilimumab $3 \mathrm{mg} / \mathrm{kg}$ group, three $(5 \%)$ due to unknown causes, one $(2 \%)$ due to subdural haematoma unrelated to study drug, one $(2 \%)$ due to sedation, one $(2 \%)$ due to hypovolaemic septic shock and septic shock from candidaemia, and one (2\%) due to abdominal sepsis and secondary intravascular disseminated coagulation; and in the nivolumab $3 \mathrm{mg} / \mathrm{kg}$ plus ipilimumab $1 \mathrm{mg} / \mathrm{kg}$ group, three (6\%) due to unknown causes, and one $(2 \%)$ due to adverse events not related to study drug.

Two patients had grade 2 limbic encephalitis: one in the nivolumab $3 \mathrm{mg} / \mathrm{kg}$ cohort (reported as not treatment-related by investigator) and one in the nivolumab $1 \mathrm{mg} / \mathrm{kg}$ plus ipilimumab $3 \mathrm{mg} / \mathrm{kg}$ cohort (reported as treatment-related by investigator); both events resolved with immunosuppressive treatment. One patient in the nivolumab $3 \mathrm{mg} / \mathrm{kg}$ cohort had grade 4 limbic encephalitis (reported as treatmentrelated by investigator) that did not resolve with intravenous immunoglobulin and corticosteroid treatment. Treatment-related pneumonitis occurred in eight patients and resolved in six of eight patients with treatment. The outcome was unknown for one patient, and one patient died.

One patient who crossed over from nivolumab $3 \mathrm{mg} / \mathrm{kg}$ to nivolumab $1 \mathrm{mg} / \mathrm{kg}$ plus ipilimumab $3 \mathrm{mg} / \mathrm{kg}$ had treatment-related grade 3 elevations in alanine aminotransferase levels (appendix p 4). Five (8\%) patients in the nivolumab $1 \mathrm{mg} / \mathrm{kg}$ plus ipilimumab $3 \mathrm{mg} / \mathrm{kg}$ cohort had grade 3 or 4 asymptomatic lipase elevations without clinical signs of pancreatitis (table 3 ).

Objective responses were observed in patients with one previous line of therapy, and in patients with two or more previous therapies (appendix p 25). Median overall survival and progression-free survival were not substantially different for patients with one versus two or more previous treatments, with the possible exception of longer progression-free survival in patients with one previous therapy receiving nivolumab $1 \mathrm{mg} / \mathrm{kg}$ plus ipilimumab $3 \mathrm{mg} / \mathrm{kg}$ (appendix pp 5-10).

In a post-hoc analysis in patients treated with a platinum agent as a first-line treatment, objective responses were achieved in patients with both platinumsensitive and platinum-resistant disease (appendix pp 11-14, 25). Among patients with platinum-sensitive disease, two (4\%) of 55 in the nivolumab $3 \mathrm{mg} / \mathrm{kg}$ cohort and two $(8 \%)$ of 25 in the nivolumab $1 \mathrm{mg} / \mathrm{kg}$ plus ipilimumab $3 \mathrm{mg} / \mathrm{kg}$ cohort received subsequent platinum-based cancer therapy. No patients with platinum-sensitive disease in the nivolumab $3 \mathrm{mg} / \mathrm{kg}$ plus ipilimumab $1 \mathrm{mg} / \mathrm{kg}$ arm received subsequent platinum-based cancer therapy.

\section{Discussion}

Our findings show that nivolumab monotherapy and nivolumab plus ipilimumab provide clinically meaningful activity and an acceptable safety profile for patients with limited-stage or extensive-stage SCLC and disease progression after at least one previous platinum-containing regimen. The prognosis for patients with progression after previous treatment with platinum-based chemotherapy is poor. Patients with advanced SCLC frequently respond to first-line therapy; however, recurrence is inevitable, and few effective options at the time of progression and in patients with platinum-resistant disease are available. Patients with extensive-stage SCLC have a 2-year survival of less than $5 \% .^{2,4,7}$

Our trial enrolled a heterogeneous patient population with platinum-sensitive or platinum-resistant disease and a range of previous lines of therapy, making comparisons with other second-line trials difficult. Responses and stable disease were seen in all treatment cohorts. Tumour regression followed both conventional and immune-related patterns of response (prolonged reduction in tumour burden in the presence of new lesions). Although the numbers of patients in subgroups were small, preliminary analysis showed similar responses between platinum-sensitive and platinumresistant subgroups, and similar activity in patients with one previous regimen and those with two or more previous regimens. Across treatment groups, responses were durable.

One phase 2 study $^{26}$ evaluated temozolomide in a similar population of patients with disease progression after one or two previous chemotherapy regimens. Although the proportions of patients achieving an objective response were similar to those shown in our study-11 (23\%) of 48 patients with platinum-sensitive disease and two (13\%) of 16 patients with 
platinum-refractory disease-the median duration of response to temozolomide was lower: 3.5 months (range 1.4-14.7) for all treated patients. Rova-T, a DLL3-targeted antibody-drug conjugate, showed antitumour activity and manageable toxicity in a phase 1 study of patients with SCLC and progression after one or two previous lines of therapy. ${ }^{27}$ An objective response was achieved in seven (44\%) of 16 patients positive for the DLL3 biomarker treated at the maximum tolerated doses.

Limitations of our study include that the study cohorts were not randomised, and the study was not powered for formal comparisons across cohorts. Baseline characteristics were generally similar across the cohorts, and although the combination treatment cohorts showed similar responses, responses seemed to be deeper with the nivolumab $1 \mathrm{mg} / \mathrm{kg}$ plus ipilimumab $3 \mathrm{mg} / \mathrm{kg}$ regimen. This dosing regimen has also been shown to be efficacious in previously untreated melanoma. ${ }^{16}$

The activity of nivolumab as monotherapy or combined with ipilimumab in patients irrespective of platinum sensitivity or line of therapy is an important aspect differentiating immune-checkpoint inhibitors from topotecan or amrubicin in SCLC. Response to topotecan depends on chemosensitivity, driven by tumour resistance mutations. ${ }^{7.8}$ By contrast, the genomically unstable nature of $\mathrm{SCLC}^{2}$ might make it sensitive to immune-checkpoint blockade via induction or restoration of a tumour antigen-driven immune response. Because few lymphocytes are observed in SCLC tumours,$^{28}$ one hypothesis is that there is a greater need to target the lymphoid compartment with CTLA-4 inhibition in addition to PD-1 inhibition to maximise the treatment effect. ${ }^{29}$

Some studies have shown increased activity of PD-1 blockade in patients with PD-L1-expressing NSCLC. However, data, including from this study, suggest that there is a lower prevalence of PD-L1 expression in SCLC versus NSCLC. ${ }^{9,10,30}$ A trial of pembrolizumab, ${ }^{30}$ a PD-1 immune-checkpoint inhibitor, reported an initial response in four (25\%) of 16 patients and durable responses in patients with PD-L1-positive extensive-stage SCLC. In our study, objective responses were observed in patients irrespective of PD-L1 expression, including deep tumour responses in patients with PD-L1 tumour expression less than 1\%. Whether PD-L1 expression is predictive of benefit in SCLC must await analysis in a larger population.

Although more than half of patients in this trial had received two or more chemotherapy regimens, 1-year overall survival (33\% for nivolumab $3 \mathrm{mg} / \mathrm{kg}$ and $43 \%$ for nivolumab $1 \mathrm{mg} / \mathrm{kg}$ plus ipilimumab $3 \mathrm{mg} / \mathrm{kg}$ ) was comparable with or better than that reported in historical trials of second-line topotecan or amrubicin. ${ }^{7,826}$ Consistent with other trials with immune-checkpoint inhibitors across multiple solid tumours, and unlike trials of topotecan, ${ }^{8}$ findings from our study showed a flattening of the overall survival curves for the nivolumab $3 \mathrm{mg} / \mathrm{kg}$ and nivolumab $1 \mathrm{mg} / \mathrm{kg}$ plus ipilimumab $3 \mathrm{mg} / \mathrm{kg}$ cohorts, suggesting a survival benefit in a subset of patients., ${ }^{9,10,12}$ However, because of the small numbers in this trial, it is difficult to determine when this occurs. Also consistent with findings from previous randomised trials of immuno-oncology agents, $, 10,12$ there seems to be a greater effect of nivolumab or ipilimumab treatment on overall survival than progression-free survival.

Adverse events were managed using established safety guidelines. ${ }^{9,10,13,16}$ Most toxic effects in the nivolumab $3 \mathrm{mg} / \mathrm{kg}$ and nivolumab $3 \mathrm{mg} / \mathrm{kg}$ plus ipilimumab $1 \mathrm{mg} / \mathrm{kg}$ cohorts were mild to moderate, with only six $(6 \%)$ patients in the nivolumab $3 \mathrm{mg} / \mathrm{kg}$ group and four (7\%) in the nivolumab $3 \mathrm{mg} / \mathrm{kg}$ plus ipilimumab $1 \mathrm{mg} / \mathrm{kg}$ group discontinuing because of toxicity. More treatment-related grade 3 or 4 adverse events occurred in the nivolumab $1 \mathrm{mg} / \mathrm{kg}$ plus ipilimumab $3 \mathrm{mg} / \mathrm{kg}$ cohort, with seven $(11 \%)$ patients discontinuing because of toxicity. This regimen was used effectively and safely in a phase 3 trial in patients with melanoma, suggesting that this schedule is feasible in patients with SCLC. ${ }^{16}$ In all cohorts, fewer treatment-related toxic effects were reported when compared with trials of topotecan or amrubicin. ${ }^{7.8}$

Three patients had limbic encephalitis, and one patient receiving nivolumab $1 \mathrm{mg} / \mathrm{kg}$ plus ipilimumab $3 \mathrm{mg} / \mathrm{kg}$ died of treatment-related myasthenia gravis. Autoimmune encephalitis and myasthenia gravis have been reported, albeit rarely, with both nivolumab and ipilimumab. ${ }^{9,31-36}$ The frequency of these events seems to be higher in patients with SCLC compared with other malignant diseases, perhaps due to the tendency for paraneoplastic neurological syndromes associated with this disease. Treatment-related pneumonitis was reported in eight patients across all the treatment cohorts and resulted in death in one patient receiving nivolumab $3 \mathrm{mg} / \mathrm{kg}$ plus ipilimumab $1 \mathrm{mg} / \mathrm{kg}$. It is crucial to closely monitor for immune-related adverse events or unmasking of previously subclinical autoimmune disease processes, with prompt implementation of safety guidelines for effective management.

On the basis of these encouraging phase $1 / 2$ data, phase 3 studies comparing nivolumab (240 mg intravenously every 2 weeks) as a flat dose or nivolumab plus ipilimumab (1 $\mathrm{mg} / \mathrm{kg}$ nivolumab and $3 \mathrm{mg} / \mathrm{kg}$ ipilimumab intravenously every 3 weeks for two 42-day cycles followed by nivolumab [240 mg intravenously every 2 weeks]) versus placebo as maintenance therapy (in patients without progression) after first-line chemotherapy (CheckMate 451, NCT02538666), and for nivolumab (240 mg every 2 weeks intravenously) versus single-agent chemotherapy as second-line therapy (CheckMate 331, NCT02481830) in SCLC were initiated and are currently ongoing. 


\section{Contributors}

EC, SJA, JAL-M, JB, PAO, MT, JPE, DJ, MCP, DTL, FdB, MAM, PAA LH, AAt, RNP, JE, IC, PB, AAm, and PS collected, analysed and interpreted data. OC designed the study, collected, analysed and interpreted the data, and designed the figures. CTH collected, analysed and interpreted the data. C-SL designed the study, analysed and interpreted the data, and designed the figures. Development of the first draft was performed by SJA and EC. All authors contributed to drafting the manuscript and provided final approval to submit for publication.

\section{Declaration of interests}

JAL-M has received personal fees from, reimbursement of trial-associated costs, and non-financial support from Bristol-Myers Squibb. PAO has received consulting fees from Amgen and Bristol-Myers Squibb, and clinical trial funding from Armo Biosciences, Bristol-Myers Squibb, Merck, and MedImmune. MT has served on advisory boards and received honoraria from Eisai and Onyx. MCP has received grant support from Bristol-Myers Squibb to conduct this study as well as personal fees from AbbVie, CelGene, Clovis Oncology, Genentech, Novartis, and grants from Novartis, OncoMed Pharmaceuticals, and Stemcentrix. DTL has received financial support from Bristol-Myers Squibb to conduct this study. FdB has served on advisory boards for and has received personal fees from Bristol-Myers Squibb, Merck, and Novartis. PAA has served as a consultant to and held an advisory role for Amgen, Bristol-Myers Squibb, Roche-Genentech, MSD, Novartis, and Ventana, as well as received research funds from Bristol-Myers Squibb, Roche-Genentech, and Ventana. LH has received research funding from AstraZeneca; served as a paid consultant for Genentech and Merck and an unpaid consultant for Bayer, Bristol-Myers Squibb, and Xcovery; and received lecture fees from Biodesix. AAm has received personal fees and grant support from Bristol-Myers Squibb. JE has received grant support from AstraZeneca, Basilea pharmaceutica, Bayer, Bristol-Myers Squibb, Celgene, Clovis, Daiichi Sankyo, Eisai, e-Therapeutics, GlaxoSmithKline, Gilead, Immunocore, Merck, Otsuka, Roche/Genentech, TC BioPharm, Verastem, and Vertex, and served on advisory boards for and received honorarium payable to the institution from Baxter, Bayer, Bristol-Myers Squibb, Celgene, Clovis, Eisai, GlaxoSmithKline, Immunova, Karus Therapeutics, Otsuka, Roche/Genentech, TC BioPharm, and Transgene/Jennerex. IC has received research grant support and personal fees from Bristol-Myers Squibb. PB has received personal fees from Bristol-Myers Squibb, GlaxoSmithKline, MSD, Novartis, and Pfizer. AAt has served on advisory boards and received honoraria from Bristol-Myers Squibb. PS has served as a consultant to Amgen, AstraZeneca, Bristol-Myers Squibb, and GlaxoSmithKline, and reports patents licensed for self to Jounce. CTH and C-SL are employed by and own stock in Bristol-Myers Squibb. OC was employed by and owned stock in Bristol-Myers Squibb. The other authors declare no competing interests.

\section{Acknowledgments}

We thank the patients and their families, as well as the participating study teams, for making this study possible; the staff of Dako North America for collaborative development of the automated immunohistochemical assay for PD-L1 assessment; Marina Tschaika for medical oversight of the study; and Michael Cunningham for serving as the protocol manager. Earlier versions of the manuscript were prepared with medical writing and editorial assistance from Britt Anderson, Vasupradha Vethantham, and Anne Cooper (StemScientific), with funding from Bristol-Myers Squibb.

\section{References}

1 National Comprehensive Cancer Network. Clinical practice guidelines in oncology. Small cell lung cancer. Version 1. http://www.nccn.org (accessed Dec 1, 2015).

2 Byers LA, Rudin CM. Small cell lung cancer: where do we go from here? Cancer 2015; 121: 664-72.

3 Hanna N, Bunn PA Jr, Langer C, et al. Randomized phase III trial comparing irinotecan/cisplatin with etoposide/cisplatin in patients with previously untreated extensive-stage disease small-cell lung cancer. J Clin Oncol 2006; 24: 2038-43.

4 Puglisi M, Dolly S, Faria A, Myerson JS, Popat S, O’Brien ME. Treatment options for small cell lung cancer-do we have more choice? Br J Cancer 2010; 102: 629-38.
5 Zatloukal P, Cardenal F, Szczesna A, et al. A multicenter international randomized phase III study comparing cisplatin in combination with irinotecan or etoposide in previously untreated small-cell lung cancer patients with extensive disease. Ann Oncol 2010; 21: 1810-16.

6 Schmittel A, Sebastian M, Fischer von Weikersthal L, et al, for the Arbeitsgemeinschaft Internistische Onkologie Thoracic Oncology Study Group. A German multicenter, randomized phase III trial comparing irinotecan-carboplatin with etoposide-carboplatin as first-line therapy for extensive-disease small-cell lung cancer. Ann Oncol 2011; 22: 1798-804.

7 Asai N, Ohkuni Y, Kaneko N, Yamaguchi E, Kubo A. Relapsed small cell lung cancer: treatment options and latest developments. Ther Adv Med Oncol 2014; 6: 69-82.

8 Von Pawel J, Jotte R, Spigel DR, et al. Randomized phase III trial of amrubicin versus topotecan as second-line treatment for patients with small-cell lung cancer. J Clin Oncol 2014; 32: 4012-19.

9 Borghaei H, Paz-Ares L, Horn L, et al. Nivolumab versus docetaxel in advanced nonsquamous non-small-cell lung cancer. $N$ Engl J Med 2015; 373: 1627-39.

10 Brahmer J, Reckamp KL, Baas P, et al. Nivolumab versus docetaxel in advanced squamous-cell non-small-cell lung cancer. $N$ Engl J Med 2015; 373: 123-35.

11 OPDIVO (nivolumab) [package insert]. Princeton, NJ: Bristol-Myers Squibb Company, 2016.

12 Hodi FS, O'Day SJ, McDermott DF, et al. Improved survival with ipilimumab in patients with metastatic melanoma. $N$ Engl J Med 2010; 363: 711-23.

13 Robert C, Thomas L, Bondarekno I, et al. Ipilimumab plus dacarbazine for previously untreated metastatic melanoma. N Engl J Med 2011; 364: 2517-26.

14 Curran MA, Montalvo W, Yagita H, Allison JP. PD-1 and CTLA-4 combination blockade expands infiltrating $\mathrm{T}$ cells and reduces regulatory $\mathrm{T}$ and myeloid cells within B16 melanoma tumors. Proc Natl Acad Sci USA 2010; 107: 4275-80.

15 Hammers HJ, Plimack ER, Infante JR, et al. Expanded cohort results from CheckMate 016: a phase I study of nivolumab in combination with ipilimumab in metastatic renal cell carcinoma (mRCC). J Clin Oncol 2015; 33 (suppl): 4516 (abstr).

16 Larkin J, Chiarion-Sileni V, Gonzalez R, et al. Combined nivolumab and ipilimumab or monotherapy in untreated melanoma. N Engl J Med 2015; 373: 23-34.

17 Rizvi NA, Gettinger SN, Goldman JW, et al. Safety and efficacy of first-line nivolumab (NIVO; anti-programmed death-1 [PD-1]) and ipilimumab in non-small cell lung cancer (NSCLC). J Thoracic Oncol 2015; 10 (9 suppl): S176 (abstr 786).

18 Eisenhauer EA, Therasse P, Bogaerts J, et al. New response evaluation criteria in solid tumours: revised RECIST guideline (version 1.1). Eur J Cancer 2009; 45: 228-47.

19 Wolchok JD, Kluger H, Callahan MK, et al. Nivolumab plus ipilimumab in advanced melanoma. N Engl J Med 2013; 369: 122-33.

20 Postow MA, Chesney J, Pavlick AC, et al. Nivolumab and ipilimumab versus ipilimumab in untreated melanoma. N Engl J Med 2015; 372: 2006-17.

21 YERVOY (ipilimumab) [package insert]. Princeton, NJ: Bristol-Myer Squibb Company; 2015.

22 Agrawal S, Feng Y, Roy A, Kollia G, Lestini B. Nivolumab dose selection: challenges, opportunities and lessons learned for cancer immunotherapy. J Immunother Cancer 2015; 3 (suppl 2): P141.

23 Phillips T, Simmons P, Inzunza HD, et al. Development of an automated PD-L1 immunohistochemistry (IHC) assay for non-small cell lung cancer. Appl Immunohistochem Mol Morphol 2015; 23: 541-49.

24 Simon R. Optimal two-stage designs for phase II clinical trials. Control Clin Trials 1989; 10: 1-10.

25 Loochtan AT, Nickolich MS, Hobson-Webb LD. Myasthenia gravis associated with ipilimumab and nivolumab in the treatment of small cell lung cancer. Muscle Nerve 2015; 52: 307-08.

26 Pietanza MC, Kadota K, Huberman K, et al. Phase II trial of temozolomide in patients with relapsed sensitive or refractory small cell lung cancer, with assessment of methylguanine-DNA methyltransferase as a potential biomarker. Clin Cancer Res 2012; 18: $1138-45$. 
27 Rudin CM, Pietanza MC, Spigel DR, et al. A DLL3-targeted ADC, rovalpituzumab tesirine, demonstrates substantial activity in a phase I study in relapsed and refractory SCLC. J Thoracic Oncol 2015; 10 (9 suppl): S192-93.

28 Wang W, Hodkinson P, McLaren F, et al. Histologic assessment of tumor-associated CD45(+) cell numbers is an independent predictor of prognosis in small cell lung cancer. Chest 2013; 143: 146-51.

29 Buchbinder EI, Desai A. CTLA-4 and PD-1 pathways: similarities, differences, and implications of their inhibition. Am J Clin Oncol 2015; 39: 98-106.

30 Ott PA, Elez Fernandez ME, Hiret S, et al. Pembrolizumab (MK-3475) in patients (pts) with extensive-stage small cell lung cancer (SCLC): Preliminary safety and efficacy results from KEYNOTE-028. J Clin Oncol 2015; 33 (suppl): 7502 (abstr).

31 Royal RE, Levy C, Turner K, et al. Phase 2 trial of single agent ipilimumab (anti-CTLA-4) for locally advanced or metastatic pancreatic adenocarcinoma. J Immunother 2010; 33: 828-33.
32 Maur M, Tomasello C, Frassoldati A, Dieci MV, Barbieri E, Conte P. Posterior reversible encephalopathy syndrome during ipilimumab therapy for malignant melanoma. J Clin Oncol 2012; 30: e76-8.

33 Boyd K, Kalladka D, Overell J, Waterston A. Ipilimumab induced encephalitis: a case report. Immunome Res 2015; 11: 092.

34 Johnson DB, Saranga-Perry V, Lavin PJ, et al. Myasthenia gravis induced by ipilimumab in patients with metastatic melanoma. J Clin Oncol 2015; 33: e122-24.

35 Liao B, Shroff S, Kamiya-Matsuoka C, Tummala S. Atypical neurological complications of ipilimumab therapy in patients with metastatic melanoma. Neuro Oncol 2014; 16: 589-93.

36 Shirai T, Sano T, Kamijo F, et al. Acetylcholine receptor binding antibody-associated myasthenia gravis and rhabdomyolysis induced by nivolumab in a patient with melanoma. Jpn J Clin Oncol 2016; 46: $86-88$. 